\title{
Overweight or obese BMI is associated with earlier, but not later survival after common acute illnesses
}

\author{
Hallie C. Prescott ${ }^{1,2^{*}}$ (D) and Virginia W. Chang ${ }^{3,4}$
}

\begin{abstract}
Background: Obesity has been associated with improved short-term mortality following common acute illness, but its relationship with longer-term mortality is unknown.

Methods: Observational study of U.S. Health and Retirement Study (HRS) participants with federal health insurance (fee-for-service Medicare) coverage, hospitalized with congestive heart failure $(N=4287)$, pneumonia $(N=4182)$, or acute myocardial infarction ( $N=2001)$, 1996-2012. Using cox proportional hazards models, we examined the association between overweight or obese BMI (BMI $\left.\geq 25.0 \mathrm{~kg} / \mathrm{m}^{2}\right)$ and mortality to 5 years after hospital admission, adjusted for potential confounders measured at the same time as BMl, including age, race, sex, education, partnership status, income, wealth, and smoking status. Body mass index (BMI) was calculated from self-reported height and weight collected at the HRS survey prior to hospitalization (a median 1.1 year prior to hospitalization). The referent group was patients with a normal BMI $\left(18.5\right.$ to $\left.<25.0 \mathrm{~kg} / \mathrm{m}^{2}\right)$.

Results: Patients were a median of 79 years old (IQR 71-85 years). The majority of patients were overweight or obese: $60.3 \%$ hospitalized for heart failure, $51.5 \%$ for pneumonia, and $61.6 \%$ for acute myocardial infarction. Overweight or obese BMI was associated with lower mortality at 1 year after hospitalization for congestive heart failure, pneumonia, and acute myocardial infarction — with adjusted hazard ratios of 0.68 (95\% Cl 0.59-0.79), 0.74 (95\% Cl: 0.64-0.84), and 0.65 (95\%Cl: 0.53-0.80), respectively. Among participants who lived to one year, however, subsequent survival was similar between patients with normal versus overweight/obese BMI.

Conclusions: In older Americans, overweight or obese BMI was associated with improved survival following hospitalization for congestive heart failure, pneumonia, and acute myocardial infarction. This association, however, is limited to the shorter-term. Conditional on surviving to one year, we did not observe a survival advantage associated with excess weight.
\end{abstract}

Keywords: pneumonia, acute myocardial infarction, congestive heart failure, obesity, hospitalization, Medicare

\section{Background}

The impact of obesity on survival from acute medical illness remains a source of debate. While obesity is associated with worse health-related outcomes overall [1], it is often associated with a short-term (e.g. in-hospital or 30-day) survival advantage after acute decompensated

\footnotetext{
* Correspondence: hprescot@med.umich.edu

1 Department of Internal Medicine, Institute for Healthcare Policy \& Innovation, University of Michigan, Ann Arbor, MI, USA

${ }^{2} V A$ Center for Clinical Management Research, HSR\&D Center of Innovation, 2800 Plymouth Rd. North Campus Research Center. Bldg 16, Rm 341E, Ann Arbor, MI, USA

Full list of author information is available at the end of the article
}

congestive heart failure (CHF) [2], pneumonia [3-5], acute myocardial infarction (AMI) [6], and hospitalizations for critical illness in general-the so-called "obesity paradox". Far less is known, however, about the association of obesity with longer-term survival. While a limited number of studies have included an extended follow-up period, they have not considered the risk of mortality conditional on surviving the shorter-term [7-9]. We hypothesized that obesity may offer short-term protection but, after surviving an initial window, may still be hazardous in the longer term given the strong association of obesity with negative health outcomes $[1,10,11]$. 
Recent meta-analyses and large observations studies have suggested that a body mass index of 25 to 35 appears to be protective in older patients [12, 13], leading some to argue that current weight control guidelines targeting a normal body mass index (18.5 to 25$)$ may be harmful to older patients [14]. However, the obesity paradox may simply be the result of confounding and bias in epidemiological studies [15], explained by unmeasured differences in patients across BMI categories. Indeed, after careful control for potential confounders, a recent study found the risk of mortality increases steeply with BMIs of 27 and higher [16]. Understanding the long-term association of obesity on survival after acute hospitalization is important to guiding weight control recommendations.

Furthermore, most prior work examining the association of obesity with survival after acute hospitalization is of variable quality and limited generalizability [17]. Much of the existing data is single-center studies, often post hoc analyses of clinical databases or randomized clinical trials with limited ability to adjust for potential confounders and exclusion of large numbers of patients with missing weight [17]. Patients' weights are generally obtained after hospital admission [17, 18], when they may be biased by acute fluid shifts. Indeed, this practice may misclassify body mass index (BMI) category in as many as $20 \%$ of patients [19]. Furthermore, many studies examine in-hospital mortality, which may be biased by discharge to nursing and long-term acute care facilities [20]. Discharge practices could plausibly be different for obese patients, who typically require more intensive nursing care for a given level of illness.

Given the high prevalence of obesity (34.6\% of US adults aged 65 years and older [21]) and limited data on longer term survival after acute hospitalization, we sought to examine the association of overweight or obese BMI on longer-term survival following three common acute illnesses-congestive heart failure, acute myocardial infarction, and pneumonia-in a national sample with long-term mortality data and height and weight measurements collected prior to hospitalization. These hospitalization diagnoses accounts for $6 \%$ of US hospitalizations and $8.4 \%$ of US hospitals costs [22].

\section{Methods}

\section{Study population}

We studied participants in the nationally representative US Health and Retirement Study (HRS), a multistage probability sample of households that is linked to Medicare Claims [23]. Medicare is a federal health insurance program available to all US citizens $\geq 65$ years, as well as to select younger individuals. Consent rate for Medicare records in about $80 \%$ [23]. Since the HRS cohort began in 1992, over 37,000 adults aged 51 years and older in 23,000 households have been enrolled [23]. The sociodemographic and racial distribution is broadly representative of the older US population [24-26]. The cohort is interviewed every two years, with a follow-up rate consistently over 90\% [23]. Survey questions focus on wealth, health, cognition, and employment [23]. Patients provided informed consent for enrollment and again for Medicare linkage.

We used Medicare claims from 1996 to 2012, and studied all persons with a hospitalization for heart failure $(\mathrm{CHF})$, pneumonia, or acute myocardial infarction (AMI) following their baseline interview. We used validated approaches to identify hospitalizations for $\mathrm{CHF}$, pneumonia, and AMI by ICD-9-CM codes in linked Medicare claims (see Additional file 1: Table S1 for complete description). We followed patients until death or date of administrative censor (December 31, 2014).

\section{Exposures and outcomes}

We sought to examine (1) the association of excess body mass index with mortality following common acute illnesses, and (2) time variation in the association. Date of death was determined from the National Death Index and confirmed by HRS interviewers and the Medicare Denominator File.

The primary exposure was overweight or obese body mass index (BMI) per World Health Organization definition (BMI $\geq 25.0 \mathrm{~kg} / \mathrm{m}^{2}$ ). The reference was normal body mass (BMI 18.5 to <25.0). In initial analyses (presented in the online supplement), we confirmed similar associations for overweight $\left(\geq 25.0\right.$ to $\left.<30.0 \mathrm{~kg} / \mathrm{m}^{2}\right)$, obese $(\geq 30.0$ to $\left.<35.0 \mathrm{~kg} / \mathrm{m}^{2}\right)$, and severely obese $\left(\geq 35.0 \mathrm{~kg} / \mathrm{m}^{2}\right)$ BMI categories relative to normal BMI, so collapsed these categories for statistical efficiency. In later analyses (also presented in the online supplement), we considered alternate and referent groups of BMI 20.0 to $<25.0 \mathrm{~kg} / \mathrm{m}^{2}$ and BMI 22.0 to $<25.0 \mathrm{~kg} / \mathrm{m}^{2}$.

We calculated BMI from self-reported height and weight collected at the HRS survey prior to hospitalization using the equation: BMI $\left(\mathrm{kg} / \mathrm{m}^{2}\right)=$ weight $(\mathrm{kg}) /$ height $^{2}\left(\mathrm{~m}^{2}\right)$. Selfreported height and weight have previously been validated against physical measures in the HRS [27]. Average reporting errors were small: $1-2 \%$ for height and $1-3 \%$ for weight [27]. Because HRS surveys occur biennially and are random in relation to hospitalization, there was a variable time lag between baseline weight measurement and hospitalization: CHF, median 1.1 years (IQR 0.6, 1.7); pneumonia, median 1.1 years (IQR 0.6, 1.7); AMI, median 1.0 year (IQR $0.5,1.5)$.

\section{Covariates}

We adjusted for age, sex, race/ethnicity, education, marital status, household wealth, household income, smoking status (current, former, never), admission year, and number 
of hospitalizations, which were abstracted from HRS surveys and linked Medicare claims. These covariates were all measured at the same time as BMI. Wealth and income were standardized to 2010 U.S. dollars using the Annual Gross Domestic Product Price Index [28], then converted to categorical variables in which category one was negative or zero assets (or income) and categories 2 through 5 were quartiles of positive assets (or income) for the entire HRS cohort. Household wealth and income were abstracted from "RAND enhanced fat file" [29], which estimates total household wealth and income using all available survey data. Giving this low rate of missingness $(<4 \%)$, we used list-wide deletion for patients with missing data. We did not adjust for medical co-morbidities in the primary analysis, as these may be viewed as mediators (not confounders) of the association between obesity and mortality, but include select co-morbidities in sensitivity analyses described below.

\section{Primary statistical analyses}

We performed a series of cox proportional hazards models-separately for the CHF, pneumonia, and AMI cohorts-predicting mortality at several time-points following hospital admission: (1) in-hospital mortality; (2) 30-day mortality; (3) 90-day mortality; (4) 1-year mortality; and (5) 5-year mortality. We examined overall mortality at each of these time points, as well as the mortality conditional on survival to the prior time point. For patients with multiple eligible hospitalizations, we included each hospitalization in the primary analyses and accounted for clustering of hospitalizations within people using clustered robust standard errors [30]. Sensitivity analyses restricting to one hospitalization are described below. We did not adjust for clustering by household since fewer than $5 \%$ of households had more than one individual with either CHF, pneumonia, or AMI hospitalization.

\section{Sensitivity analyses}

We performed multiple sensitivity analyses. In the first sensitivity analysis, we performed a cox proportional hazards model adjusting for the same potential confounders as in the primary analysis, but excluded patients with declining or unknown BMI trajectories prior to hospitalization. We did this sensitivity analysis because normal BMI may be confounded by illness-associated weight loss, which is indicative of poor health and increased risk for death [31]. For this analysis, we defined declining BMI trajectory as a decline in BMI by 1.0 or more between the two HRS surveys immediately preceding hospitalization.

In the second sensitivity analysis, we performed a cox proportional hazards model with adjustment for severity of illness (acute organ failures and intensive care use) in addition to the covariates included in the primary analysis. We did this sensitivity analysis because the threshold for hospitalization may vary by BMI, such that overweight and obese patients are more likely to be hospitalized with a lower severity of illness.

In the third sensitivity analysis, we performed a multivariable logistic regression model. In addition to testing the robustness of our findings to an alternate modeling approach, the multivariable logistic regression also facilitated calculating adjusted rates of mortality by BMI category.

In the fourth sensitivity analysis, we performed a cox proportional hazards identical to the primary analysis, but only one randomly selected hospitalization per person. This approach prevents multiple observations per person. We examined a randomly selected, rather than first, hospitalization for each person because we felt that first hospitalizations would not necessarily be representative of all CHF, pneumonia, or AMI hospitalizations.

In the fifth sensitivity analysis, we matched patients with normal and overweight or obesity one-to-one by age and sex. We then performed a cox proportional hazards model on matched patients, adjusting for the same potential confounders as in the primary analysis. We did this sensitivity analysis because the wide imbalance in age between normal and overweight or obesity patients may increase risk for residual confounding.

In the sixth sensitivity analysis, we adjusted for premorbid functional disability (count of limitations of activities and instrumental activities of daily living) and select comorbidities associated with weight loss (metastatic cancer, chronic obstructive pulmonary disease, congestive heart failure, dementia, and cerebrovascular disease) that may confound the relationship between obesity and mortality.

All analyses were conducted with Stata MP software version 14 (StataCorp, College Station, TX). We used twosided significance testing and considered a $p$ value less than 0.05 to be significant. The University of Michigan Institutional Review Board approved this study.

\section{Results}

\section{CHF, pneumonia, and AMI hospitalizations}

We identified 4287 CHF hospitalizations, 4182 pneumonia hospitalizations, and 2001 AMI hospitalizations for inclusion in the study (Additional file 1: Figure S1, Table 1). The cohorts were elderly (median age 77-79) and predominantly white $(75-84 \%)$, with multiple medical comorbidities (median weighted Charlson Index 3-4). Median BMI was 25-26 across the cohorts, and 52\%-62\% of subjects were overweight or obese. Overall 30-day mortality was $10.2 \%$ (95\% CI: 9.3\%-11.1\%), $17.4 \%$ (95\% CI: $16.2 \%-18.6 \%$ ), and $15.6 \%$ (95\% CI: $14.0 \%-17.3 \%$ ) in the CHF, pneumonia, and AMI cohorts, respectively. 1-year mortality was $40.1 \%(38.6 \%-41.6 \%), 40.9 \%(39.4 \%-42.4 \%)$, and $31.9 \%(29.9 \%-34.0 \%)$. 
Table 1 Characteristics of patients and hospitalizations, by cohort

\begin{tabular}{|c|c|c|c|}
\hline \multirow{2}{*}{$\begin{array}{l}\text { Patient and Hospitalization } \\
\text { Characteristics }\end{array}$} & \multicolumn{3}{|l|}{ Cohort } \\
\hline & $\begin{array}{l}\text { CHF } \\
N=4287\end{array}$ & $\begin{array}{l}\text { Pneumonia } \\
N=4182\end{array}$ & $\begin{array}{l}\text { Acute Ml } \\
N=2001\end{array}$ \\
\hline Age (years), median (IQR) & $79(72-86)$ & $79(71-85)$ & $77(71-84)$ \\
\hline Male, N (\%) & 1841 (42.9\%) & 2007 (48.0\%) & $1051(52.5 \%)$ \\
\hline \multicolumn{4}{|l|}{ Race, N (\%) } \\
\hline White/Caucasian & $3225(75.2 \%)$ & 3417 (81.7\%) & $1670(83.5 \%)$ \\
\hline Black/African American & $934(21.8 \%)$ & $628(15.0 \%)$ & $258(12.9 \%)$ \\
\hline Other & $128(3.0 \%)$ & $137(3.3 \%)$ & $73(3.7 \%)$ \\
\hline Married/partnered, N (\%) & 1957 (45.7\%) & 1967 (47.0\%) & $1103(55.1 \%)$ \\
\hline \multicolumn{4}{|l|}{ Wealth, N (\%) } \\
\hline Net negative or zero & $592(13.8 \%)$ & 555 (13.3\%) & $208(10.4 \%)$ \\
\hline Quartile 1 & $1478(34.5 \%)$ & 1379 (33.0\%) & $559(27.9 \%)$ \\
\hline Quartile 2 & 1023 (23.9\%) & 1013 (24.2\%) & $463(23.1 \%)$ \\
\hline Quartile 3 & $682(15.9 \%)$ & $688(16.5 \%)$ & $432(21.6 \%)$ \\
\hline Quartile 4 & $512(11.9 \%)$ & $547(13.1 \%)$ & $339(16.9 \%)$ \\
\hline \multicolumn{4}{|l|}{ Income, N (\%) } \\
\hline None & $1633(38.1 \%)$ & $1604(38.4 \%)$ & $684(34.2 \%)$ \\
\hline Quartile 1 & $1467(34.2 \%)$ & 1385 (33.1\%) & $632(31.6 \%)$ \\
\hline Quartile 2 & $831(19.4 \%)$ & $753(18.0 \%)$ & 399 (19.9\%) \\
\hline Quartile 3 & $257(6.0 \%)$ & $330(7.9 \%)$ & $219(10.9 \%)$ \\
\hline Quartile 4 & $99(2.3 \%)$ & $110(2.6 \%)$ & $67(3.4 \%)$ \\
\hline \multicolumn{4}{|l|}{ Body Mass Index, N (\%) } \\
\hline Underweight & 165 (3.9\%) & $294(7.0 \%)$ & $71(3.6 \%)$ \\
\hline Normal & 1538 (35.9\%) & $1736(41.5 \%)$ & $698(34.9 \%)$ \\
\hline Overweight/obese & $2584(60.3 \%)$ & $2152(51.5 \%)$ & $1232(61.6 \%)$ \\
\hline $\begin{array}{l}\text { Body mass index, } \\
\text { median (IQR) }\end{array}$ & $26(23-30)$ & $25(22-29)$ & $26(23-29)$ \\
\hline \multicolumn{4}{|l|}{ Co-morbidities } \\
\hline $\begin{array}{l}\text { Weighted Charlson } \\
\text { Index, median (IQR) }\end{array}$ & $4(3-6)$ & $3(2-5)$ & $3(2-5)$ \\
\hline Heart Failure, N(\%) & $4278(100 \%)$ & 2080 (49.7\%) & $1106(55.3 \%)$ \\
\hline Dementia, N (\%) & $303(7.1 \%)$ & $533(12.8 \%)$ & $111(5.6 \%)$ \\
\hline Metastatic Cancer, N (\%) & $86(2.0 \%)$ & $206(4.9 \%)$ & $29(1.5 \%)$ \\
\hline \multicolumn{4}{|l|}{ Smoking Status } \\
\hline Current, N (\%) & $473(11.0 \%)$ & $601(14.4 \%)$ & $284(14.2 \%)$ \\
\hline Former, N (\%) & 2167 (50.7\%) & $2263(54.1 \%)$ & $970(48.5 \%)$ \\
\hline Never, N (\%) & $1647(38.4 \%)$ & $1318(31.5 \%)$ & $747(37.3 \%)$ \\
\hline $\begin{array}{l}\text { Hospital Length of Stay } \\
\text { (days), median (IQR) }\end{array}$ & $5(3-7)$ & $5(3-8)$ & $5(3-8)$ \\
\hline Used Intensive Care, N (\%) & 974 (22.7\%) & 849 (20.3\%) & $1158(57.9 \%)$ \\
\hline \multicolumn{4}{|l|}{ Mortality, N (\%) } \\
\hline In-hospital & $191(4.5 \%)$ & $455(10.8 \%)$ & $200(10.0 \%)$ \\
\hline 30 days & $437(10.2 \%)$ & 727 (17.4\%) & $312(15.6 \%)$ \\
\hline 90 days & 860 (20.1\%) & $1072(25.6 \%)$ & $411(20.5 \%)$ \\
\hline 1 year & $1720(40.1 \%)$ & 1710 (40.9\%) & $639(31.9 \%)$ \\
\hline
\end{tabular}

Compared to patients with normal BMI, Patients with overweight or obese BMI were younger, less wealthy, and more likely to be male, married or partnered, and Black/African American (Additional file 1: Tables S2, Additional file 1: Table S3, Additional file 1: Table S4). In unadjusted comparisons, 30-day, 90-day, and 1-year mortality were lower in overweight and obese patients $(p<0.001$ for each cohort). For example, 1-year mortality was $48.1 \%$ versus $33.8 \%$ after CHF hospitalization; $45.2 \%$ versus $34.8 \%$ after pneumonia hospitalizations; and $39.7 \%$ versus $25.6 \%$ after AMI hospitalization. Underweight patients had the highest 1-year mortality: $64.9 \%, 59.9 \%$, and $66.2 \%$ following CHF, pneumonia, and AMI hospitalizations, respectively.

\section{Association of Overweight or obese BMI with mortality}

In multivariable cox regression accounting for potential confounders, overweight or obese BMI was independently associated with a lower hazard of 90-day, 1-year, and 5-year mortality following congestive heart failure, pneumonia, and acute myocardial infarction hospitalizations relative to a normal BMI $\left(18.5\right.$ to $\left.<25.0 \mathrm{~kg} / \mathrm{m}^{2}\right)$, $p<0.05$ for each association (Table 2). Overweight or obese BMI was also associated with lower hazard of inhospital and 30-day mortality following CHF and pneumonia hospitalizations.

\section{Association of Overweight or obese BMI with mortality, conditional on survival to 1 year}

Among patients who survived to 1 year following acute illness, adjusted hazards of 5 -year mortality were indistinguishable between patients with overweight or obese BMI versus patients normal BMI: adjusted $\mathrm{HR}$ for 5-year mortality 0.98 (95\% CI: 0.84,1.14) in CHF, 0.92 (95\% CI: $0.81,1.05)$ in pneumonia, and $0.90(0.71,1.13)$ in AMI survivors (Table 3 ), $p>0.05$ for all associations.

\section{Sensitivity analyses}

The association between overweight or obese BMI and lower 1-year mortality persisted in each of the six sensitivity analyses and for all three cohorts (Fig. 1, Additional file 1: Table S5).

In multivariable logistic regression, adjusted 1-year mortality following CHF hospitalization was 34.8\% (95\% CI: $32.3 \%, 37.3 \%)$ in overweight and obese patients versus $46.3 \%$ (95\% CI: $42.8 \%, 49.8 \%)$ in normal weight patients, an absolute decline of $11.5 \%$ (95\% CI: $7.1 \%$, $15.8 \%) p<0.001$. Adjusted 1 -year mortality was $35.7 \%$ (95\% CI: $33.4 \%, 38.0 \%$ ) versus $44.2 \%$ (95\% CI: $41.4 \%$, 47.0\%) following pneumonia hospitalizations, an absolute decline of $8.5 \%$ (95\% CI: 4.8\%, 12.2\%) $p<0.001$. Adjusted 1 -year mortality was $27.0 \%$ (95\% CI: $24.2 \%, 29.8 \%$ ) versus 37.4\% (95\% CI: 33.4\%, 41.3\%) following AMI hospitalizations, an absolute decline of $10.4 \%(5.4 \%, 15.3 \%) p<0.001$. 
Table 2 Association of Overweight or Obese BMI with Mortality, by Time-Period

\begin{tabular}{|c|c|c|c|c|c|}
\hline & Time-Period & & & & \\
\hline Type of Hospitalization & $\begin{array}{l}\text { In-hospital } \\
\text { aHR ( } 95 \% \mathrm{Cl})\end{array}$ & $\begin{array}{l}\text { 30-Day } \\
\text { aHR (95\% Cl) }\end{array}$ & $\begin{array}{l}\text { 90-Day } \\
\text { aHR (95\% Cl) }\end{array}$ & $\begin{array}{l}\text { 1-Year } \\
\text { aHR }(95 \% \mathrm{Cl})\end{array}$ & $\begin{array}{l}\text { 5-Year } \\
\text { aHR }(95 \% \mathrm{Cl})\end{array}$ \\
\hline Congestive Heart Failure & $\begin{array}{l}\mathbf{0 . 5 4} \\
(0.39-0.75)\end{array}$ & $\begin{array}{l}\mathbf{0 . 7 5} \\
(0.61-0.93)\end{array}$ & $\begin{array}{l}\mathbf{0 . 6 9} \\
(0.59-0.82)\end{array}$ & $\begin{array}{l}\mathbf{0 . 6 8} \\
(0.59-0.79)\end{array}$ & $\begin{array}{l}\mathbf{0 . 7 9} \\
(0.70-0.90)\end{array}$ \\
\hline Pneumonia & $\begin{array}{l}\mathbf{0 . 7 5} \\
(0.61-0.92)\end{array}$ & $\begin{array}{l}\mathbf{0 . 6 9} \\
(0.58-0.82)\end{array}$ & $\begin{array}{l}\mathbf{0 . 7 0} \\
(0.60-0.81)\end{array}$ & $\begin{array}{l}\mathbf{0 . 7 4} \\
(0.64-0.85)\end{array}$ & $\begin{array}{l}\mathbf{0 . 8 2} \\
(0.73-0.91)\end{array}$ \\
\hline Acute Myocardial Infarction & $\begin{array}{l}0.81 \\
(0.56-1.15)\end{array}$ & $\begin{array}{l}\mathbf{0 . 7 7} \\
(0.59-1.00)\end{array}$ & $\begin{array}{l}\mathbf{0 . 7 8} \\
(0.61-1.00)\end{array}$ & $\begin{array}{l}\mathbf{0 . 6 5} \\
(0.53-0.80)\end{array}$ & $\begin{array}{l}\mathbf{0 . 7 4} \\
(0.63-0.87)\end{array}$ \\
\hline
\end{tabular}

Adjusted hazard ratios reflect the odds of mortality during any day from hospital admission to the end-point. The referent group in $\mathrm{BMI} 18.5$ to $<25.0 \mathrm{~kg} / \mathrm{m}^{2}$. The models adjust for age, sex, race, marital status, education, smoking status, admission year, number of hospitalizations, household wealth, and household income Bolded numbers are statistically significant, $p<0.05$

There was no significant association detected between overweight or obesity and 5-year survival, among patients who survive to one-year, for all sensitivity analyses.

Results were also similar when considering more granular categories of BMI (Additional file 1: Table S6). For example, adjusted HR for 1-year mortality after CHF hospitalization was 0.66 (95\% CI: 0.56, 0.79), 0.71 (0.57, $0.89)$, and $0.70(0.54,0.91)$ among overweight, obese, and severely obese BMI, respectively. Adjusted HR for 5-year mortality, conditional on survival to 1 year after CHF was 0.95 (95\% CI: 0.80, 1.13), 1.09 (0.89, 1.34), and 0.90 (0.66, 1.20) among overweight, obese, and severely obese BMI, respectively.

Results were also similar when using BMI 20.0 to < $25.0 \mathrm{~kg} / \mathrm{m}^{2}$ as the referent group (Additional file 1 : Table S7). Adjusted HR for 1-year mortality were 0.70 (95\% CI: 0.60, 0.82), 0.77 (95\% CI: 0.67, 0.89), and 0.67 (95\% CI: $0.53,0.85$ ) after CHF, pneumonia, and AMI hospitalization, respectively. Adjusted HR for 5-year mortality, conditional on survival to 1 year, were 1.03 (95\% CI: 0.88, 1.21), 0.98 (0.85, 1.13), and 0.89 (0.71, 1.13) after CHF, pneumonia, and AMI hospitalization, respectively. However, when using BMI 22.0 to < $25.0 \mathrm{~kg} / \mathrm{m}^{2}$ as the referent group, the protective association of overweight and obese BMIs after CHF and pneumonia hospitalization was attenuated; adjusted HRs for 1-year mortality were 0.74 (95\% CI: $0.62,0.88$ ) and 0.85 (95\% CI: 0.71, 1.00) after CHF and pneumonia hospitalizations, respectively.

\section{Discussion}

In this national sample of older Americans, we have shown that overweight or obese BMI is common among patients hospitalized with CHF, pneumonia, and AMI. Over half of all patients in this study had a BMI greater than 25 . We found that overweight or obese BMIs were independently associated with decreased short-term mortality up to one year following hospitalization for CHF, pneumonia, and AMI, relative to normal BMI $\left(18.5\right.$ to $\left.<25.0 \mathrm{~kg} / \mathrm{m}^{2}\right)$. Adjusted rates of 1-year mortality were about $10 \%$ lower in overweight and obese patients, relative to normal weight patients, across each of the three cohorts. Our findings were robust to several sensitivity analyses, including analyses that accounted for BMI trajectory prior to hospitalization and severity of illness during hospitalization. They were also robust to direct standardization for age and sex in a matched analysis. The protective association of overweight and obese BMI was slightly attenuated when using a referent group of BMI 22.0 to $<25.0 \mathrm{~kg} / \mathrm{m}^{2}$, suggesting that some - but not all - of the protective association may be due to increased risk of mortality for patients with low-normal BMI.

Table 3 Association of overweight or obese BMI with conditional mortality

\begin{tabular}{|c|c|c|c|c|}
\hline \multirow[b]{2}{*}{ Type of Hospitalization } & \multicolumn{4}{|l|}{ Time-Period } \\
\hline & $\begin{array}{l}\text { 30-Day } \\
\text { aHR (95\% Cl) }\end{array}$ & $\begin{array}{l}\text { 90-Day } \\
\text { aHR (95\% Cl) }\end{array}$ & $\begin{array}{l}\text { 1-Year } \\
\text { aHR (95\% Cl) }\end{array}$ & $\begin{array}{l}\text { 5-Year } \\
\text { aHR (95\% CI) }\end{array}$ \\
\hline Congestive Heart Failure & $\begin{array}{l}0.83 \\
(0.64-1.09)\end{array}$ & $\begin{array}{l}\mathbf{0 . 6 8} \\
(0.54-0.85)\end{array}$ & $\begin{array}{l}\mathbf{0 . 7 0} \\
(0.57-0.85)\end{array}$ & $\begin{array}{l}0.98 \\
(0.84-1.14)\end{array}$ \\
\hline Pneumonia & $\begin{array}{l}\mathbf{0 . 6 0} \\
(0.46-0.78)\end{array}$ & $\begin{array}{l}\mathbf{0 . 7 4} \\
(0.58-0.94)\end{array}$ & $\begin{array}{l}\mathbf{0 . 8 0} \\
(0.66-0.97)\end{array}$ & $\begin{array}{l}0.92 \\
(0.81-1.05)\end{array}$ \\
\hline Acute Myocardial Infarction & $\begin{array}{l}0.60 \\
(0.38-0.95)\end{array}$ & $\begin{array}{l}0.65 \\
(0.40-1.05)\end{array}$ & $\begin{array}{l}\mathbf{0 . 5 3} \\
(0.38-0.72)\end{array}$ & $\begin{array}{l}0.90 \\
(0.71-1.13)\end{array}$ \\
\hline
\end{tabular}

Adjusted hazard ratios reflect odds of mortality for the time-period, conditional on survival to the prior time-period. For example, 30-day mortality is the hazard ratio for 30-day mortality, conditional survival to hospital discharge; 90-day mortality is the hazard ratio of 90-day mortality, conditional survival to 30 days. The referent group in BMI 18.5 to $<25.0 \mathrm{~kg} / \mathrm{m}^{2}$. The models adjust for age, sex, race, marital status, education, smoking status, admission year, number of hospitalizations, household wealth, and household income

Bolded numbers are statistically significant, $p<0.05$ 


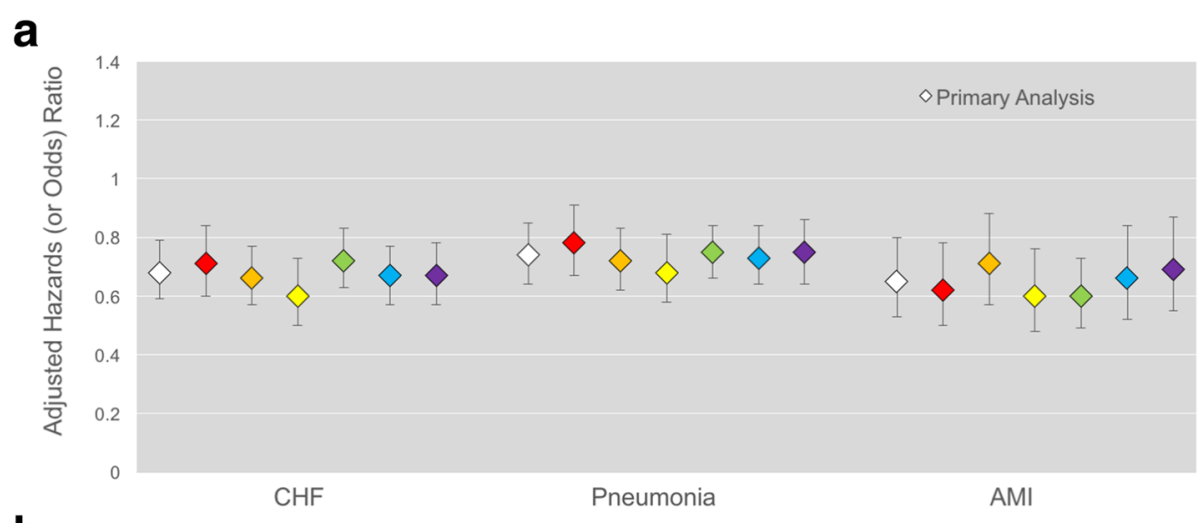

b

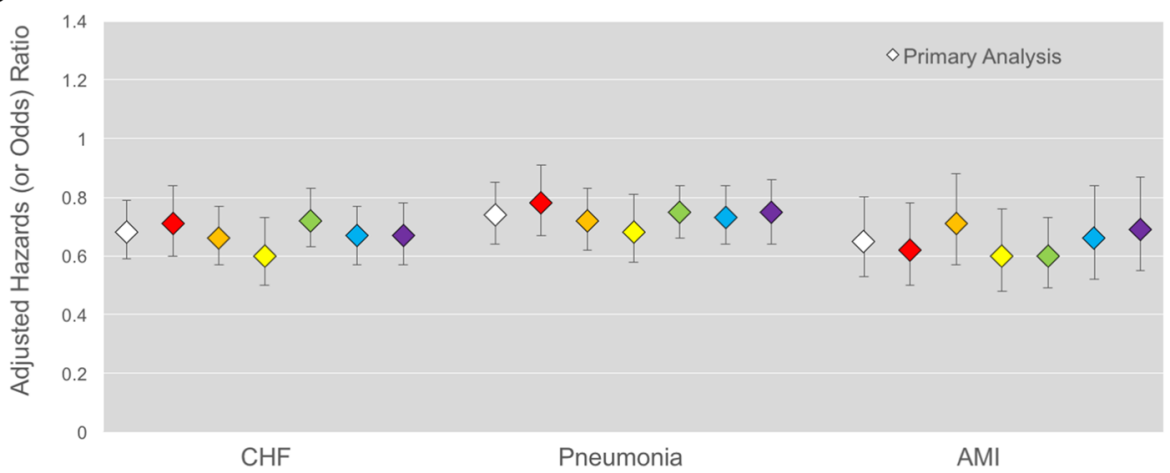

Fig. 1 Adjusted Hazard (and Odds) Ratios for Mortality in Primary and Sensitivity Analyses Panel a shows 1-year mortality results. Panel b shows 5-year mortality, conditional on survival to one year. The adjusted hazard ratio of overweight or obese BMl, relative to normal BMl $\left(18.5\right.$ to $\left.<25.0 \mathrm{~kg} / \mathrm{m}^{2}\right)$ is shown. The primary analysis is in white, while sensitivity analyses are shown in color: $(1$, red) excluding patients with unknown BMI trajectory or declining BMI trajectory prior to hospitalization; (2, orange) adjusting for acute illness severity; (3, yellow) logistic regression model; (4, green) include just one randomly selected hospitalization per person; (5, blue) analysis of age- and sex-matched pairs; and (6, purple) adjustment for pre-morbid disability and select co-morbidities. All models adjust for age, sex, race, marital status, education, smoking status, admission year, number of hospitalizations, household wealth, and household income.Error bars represent the $95 \% \mathrm{Cl}$ for the hazard (or odds) ratio. A hazard or odds ratio of 1.0 indicates no association. A hazard ratio $>1.0$ represents a positive association (overweight or obese BMI is associated with greater mortality), while a hazard ratio $<1.0$ represents a negative association (overweight or obese BMl is associated with lower mortality)

Importantly, we find that the protective effect of overweight or obese BMI does not extend into the longer term. Among patients hospitalized with CHF, pneumonia, and AMI who survived to one year, the association between overweight or obese BMI and 5-year mortality was not statistically significant in any of our analyses.

While our findings are consistent with several prior studies showing that obesity is associated with decreased in-hospital and short-term mortality following acute medical illnesses [2, 6, 18], less is known about whether such a potential advantage would extend into longer-term mortality. While there are some studies that examined longer-term survival after admission, they did not model the risk of mortality conditional on surviving the shorter-term [7-9]. Data on longer-term mortality is of central importance to the evaluation of clinical guidelines for weight management. For example, obesity may be protective against in-hospital mortality but, conditional on surviving the short term, still be hazardous for longer-term mortality. To our knowledge, this study is among the first to examine conditional, longer-term survival.

There are several biological hypotheses for why obesity may be protective during acute illness. First, while obesity is associated with greater inflammation during times of health, it also modulates the pro-inflammatory response to acute illness. In patients with acute lung injury, obesity is associated with lower levels of pro-inflammatory cytokines [32]. Obese patients have a decreased catecholamine response to stress [33]. Furthermore, adipose tissue serves as a storage reservoir for M2 macrophages, which have a protective anti-inflammatory phenotype during critical illness [34]. A recent prospective study of pneumonia patients by Singanayagam, et al., however, found that obese patients had better 30-day survival despite higher rates of sepsis and higher levels of c-reactive protein (markers of greater systemic inflammation) [5]. Moreover, Braun,et al. have recently reported improved survival in obese patients with community-acquired pneumonia, despite similar levels of c-reactive protein, white blood cell 
count, and procalcitonin [7]. Together, these studies suggest that alternative or additional mechanisms are likely to be involved in the protective effect.

Second, obesity may be associated with improved host response to bacterial infection. Leptin is produced by adipose tissue, modulates the immune response, and tightly correlates with BMI [35]. Leptin-deficient mice die when exposed to bacterial challenge [35].

Third, obese patients may be better poised to tolerate the catabolic stress associated with critical illness. Herridge, et al. found that patients surviving acute respiratory distress syndrome lost an average $18 \%$ of their body weight during hospitalization, and many did not return to their baseline weight by one year of follow-up [36]. This degree of acute weight loss is likely to be better tolerated by patients with a higher BMI.

Lastly, it is possible that the association it not due to a protective effect of overweight or obesity, but rather, is due to differences in the clinical presentation and/or treatment in overweight and obese patients. For example, obesity is associated with lower pulmonary reserve [37], so obese patients may become symptomatic and present earlier in their course or heart failure or pneumonia. In acute myocardial infarction, obese patients are less likely to have extensive coronary disease and left ventricular dysfunction [38]. Obese patients may also get more aggressive acute treatment, especially in cardiovascular disease, where obesity itself is viewed as a major risk factor. In two studies of patients admitted for ischemic heart disease, obese patients were more likely to receive guideline recommended therapy and undergo revascularization procedures, after adjusting for clinical risk $[39,40]$.

Again, we find that the protective association of excess weight is short-term and diminishes beyond one year, which is consistent with the potential biological mechanisms of benefit. Obesity may help blunt an acute inflammatory response, mediate host response to infection, and provide resilience during catabolic stress, but once these threats have resolved, obesity may cease to be protective. Thus, our findings suggest that weight control guidelines should not be reversed, as any survival benefit associated with obesity is short-term. Moreover, despite our sensitivity analyses, any residual confounding due to weight loss from severe illness is more likely to manifest in short-term mortality.

There are several limitations to our study. First, we used self-reported height and weight, which may contribute to underestimation of BMI. However, a prior analysis of the HRS cohort suggests that the magnitude of reporting errors is small [27]. Additional measures of adiposity (e.g. bioelectrical impedance, waist circumference)-which may better reflect fat mass and distribution-were not available. Secondly, CHF, pneumonia, and AMI hospitalizations were identified by ICD-9-CM codes in Medicare claims. While we used commonly employed and validated definitions, there still may be misspecification in both directions. Third, while we were able to adjust for many potential confounders not typically available in clinical or administrative data sources (e.g. household wealth and education), we could not adjust for differences in illness severity on hospital presentation beyond the crude measures of acute organ dysfunction and intensive care use. We were also unable to adjust for differences in treatment. Fourth, because HRS surveys pre-dated hospitalization by an average of one year, dynamic variables such as weight and number of functional limitations may not precisely reflect the patient's status at the time of hospital admission. Weight at the time of admission, however, is more likely to reflect an acute fluid imbalance for some of our conditions. Fifth, because our data are from 1996 to 2012, they may not accurately represent current Medicare beneficiaries.

\section{Conclusions}

In older Americans, overweight or obese BMI was associated with improved survival to 1 year following hospitalization for congestive heart failure, pneumonia, and acute myocardial infarction. Conditional on surviving to one year after admission, however, there is no survival advantage to 5 years associated with overweight or obese BMI.

\section{Additional file}

Additional file 1: Online Supplement; Contains supplemental Tables S1-S7 and supplemental Figure S1. (PDF 376 kb)

\section{Abbreviations}

AMI: Acute myocardial infarction; BMI: body mass index; CHF: congestive heart failure; HRS: Health \& Retirement Study; ICD-9-CM: International Classification of Diseases, 9th Edition, Clinical Modification; ICU: Intensive Care Unit; US: United States

\section{Acknowledgements}

The views expressed in this article are those of the authors and do not necessarily reflect the position or policy of the Department of Veterans Affairs or the US government.

\section{Funding}

This work was supported by grants K08 GM115859 from the National Institutes of Health [HCP] and 7-12-CT-12 from the American Diabetes Association [WWC]. The Health and Retirement Study is sponsored by the National Institute on Aging (U01 AG009740) and performed at the Institute for Social Research, University of Michigan. The funders were not involved in the design, conduct, or reporting of the study.

\section{Availability of data and materials}

Survey data from the health and retirement study is publically available at http://hrsonline.isr.umich.edu. Linked Medicare claims can be purchased through Center for Medicare and Medicaid services.

Authors' contributions

HCP designed the study, analyzed the data, interpreted the data, and drafted the manuscript. HCP takes full responsibility for the content of the manuscript including data and analysis. VC designed the study, interpreted the data, and 
edited the manuscript for critical intellectual content. Both authors read and approved the final manuscript.

\section{Ethics approval and consent to participate}

University of Michigan IRB approved this study. Written or verbal informed consent was obtained on enrollment into Health and Retirement Study (HRS). (For each wave of HRS survey, half of the surveys are done in person and half are done over the telephone. Thus, because many participants' first surveys are completed by telephone and not in person, these participants complete verbal consent for enrollment in the study, and this mode of consent was approved by the IRB). Because participants are enrolled from the community at the ages for 51-54 years, there is a very low rate of cognitive impairment at the time of enrollment into the study. However, if it is determined that a participant has cognitive impairment, then informed consent is obtained from a proxy. In addition to providing consent for enrollment into HRS, participants also provided informed consent (always written) for linkage to Medicare records.

\section{Consent for publication}

Not applicable.

\section{Competing interests}

The authors have no relevant potential conflicts of interest to disclose.

\section{Publisher's Note}

Springer Nature remains neutral with regard to jurisdictional claims in published maps and institutional affiliations.

\section{Author details}

'Department of Internal Medicine, Institute for Healthcare Policy \& Innovation, University of Michigan, Ann Arbor, MI, USA. VA Center for Clinical Management Research, HSR\&D Center of Innovation, 2800 Plymouth Rd. North Campus Research Center. Bldg 16, Rm 341E, Ann Arbor, MI, USA. ${ }^{3}$ Department of Social and Behavioral Sciences, NYU College of Global Public Health, New York, NY, USA. ${ }^{4}$ Department of Population Health, NYU School of Medicine, New York, NY, USA.

Received: 23 June 2017 Accepted: 23 January 2018

\section{Published online: 06 February 2018}

\section{References}

1. Adams KF, et al. Overweight, obesity, and mortality in a large prospective cohort of persons 50 to 71 years old. N Engl J Med. 2006;355:763-78.

2. Fonarow GC, Srikanthan P, Costanzo MR, Cintron GB, Lopatin M. An obesity paradox in acute heart failure: analysis of body mass index and inhospital mortality for 108927 patients in the acute Decompensated heart failure National Registry. Am Heart J. 2007;153:74-81.

3. King $P$, et al. Impact of obesity on outcomes for patients hospitalised with pneumonia. Eur Respir J. 2013;41:929-34.

4. Kahlon S, et al. Obesity and outcomes in patients hospitalized with pneumonia. Clin Microbiol Infect Off Publ Eur Soc Clin Microbiol Infect Dis. 2013;19:709-16.

5. Singanayagam A, Singanayagam A, Chalmers JD. Obesity is associated with improved survival in community-acquired pneumonia. Eur Respir J. 2013:42:180-7.

6. Bucholz EM, et al. Body mass index and mortality in acute myocardial infarction patients. Am J Med. 2012:125:796-803.

7. Braun $\mathrm{N}$, et al. Obesity paradox in patients with community-acquired pneumonia: is inflammation the missing link? Nutr Burbank Los Angel Cty Calif. 2017:33:304-10

8. Bucholz EM, Beckman AL, Krumholz HA, Krumholz HM, Dr. Bucholz was affiliated with the Yale School of Medicine and Yale School of Public Health during the time that the work was conducted. Excess weight and life expectancy after acute myocardial infarction: the obesity paradox reexamined. Am Heart J. 2016;172:173-81.

9. O'Brien EC, et al. Association of body mass index and long-term outcomes in older patients with non-ST-segment-elevation myocardial infarction: results from the CRUSADE registry. Circ Cardiovasc Qual Outcomes. 2014;7:102-9.
10. Calle EE, Rodriguez C, Walker-Thurmond K, Thun MJ. Overweight, obesity, and mortality from cancer in a prospectively studied cohort of U.S. adults. N Engl J Med. 2003;348:1625-38.

11. GBD 2015 Obesity Collaborators, et al. Health effects of overweight and obesity in 195 countries over 25 years. N Engl J Med. 2017;377:13-27.

12. Lu JL, et al. Association of age and BMI with kidney function and mortality: a cohort study. Lancet Diabetes Endocrinol. 2015;3:704-14.

13. Flegal KM, Kit BK, Orpana H, Graubard BI. Association of all-cause mortality with overweight and obesity using standard body mass index categories: a systematic review and meta-analysis. JAMA. 2013;309:71-82.

14. Dixon JB, Egger GJ, Finkelstein EA, Kral JG, Lambert GW. 'Obesity paradox' misunderstands the biology of optimal weight throughout the life cycle. Int J Obes. 2015;2005(39):82-4

15. Stevens J, Bradshaw PT, Truesdale KP, Jensen MD. Obesity paradox should not interfere with public health efforts. Int J Obes. 2015:2005(39):80-1.

16. Bowman $\mathrm{K}$, et al. Obesity in older people with and without conditions associated with weight loss: follow-up of 955,000 primary care patients. J Gerontol A Biol Sci Med Sci. 2017;72:203-9.

17. Kiraly L, Hurt RT, Van Way CW. The outcomes of obese patients in critical care. JPEN J Parenter Enteral Nutr. 2011;35:29-35.

18. Nie W. et al, Obesity survival paradox in pneumonia: a meta-analysis. https://doi.org/10.1186/1741-7015-12-61.

19. O'Brien JM Jr, et al. The association between body mass index, processes of care, and outcomes from mechanical ventilation: a prospective cohort study. Crit Care Med. 2012:40:1456-63.

20. Hall WB, Willis LE, Medvedev S, Carson SS. The implications of long-term acute care hospital transfer practices for measures of in-hospital mortality and length of stay. Am J Respir Crit Care Med. 2012;185:53-7.

21. Products - Data Briefs - Number 106 - September 2012. Available at: https://www.cdc.gov/nchs/products/databriefs/db106.htm. (Accessed: 26 Oct 2017).

22. Torio, C. \& Moore. National Inpatient Hospital Costs: The Most Expensive Hospital Conditions by Payer, 2013. HCUP Statistical Brief \#204. Agency for Healthcare Research and Quality, Rockville, MD. (2016). Available at: https:// hcup-us.ahrq.gov/reports/statbriefs/sb204-Most-Expensive-HospitalConditions.pdf. (Accessed: 14 Feb 2017).

23. Sonnega A, Faul JD, Ofstedal MB, Langa KM, Phillips JW, Weir DR. Cohort Profile: Health and Retirement Study (HRS). Int J Epidemiol. 2014:43(2):57685. doi:https://doi.org/10.1093/ije/dyu067.

24. Meijer $\mathrm{E}$, Karoly LA. Representativeness of the low-income population in the health and retirement study. The J Econ Ageing. 2013;9:90-99. doi:https:// doi.org/10.1016/j.jeoa.2016.08.004.

25. Ofstedal MB, Weir DR. Recruitment and retention of minority participants in the health and retirement study. The Gerontologist. 2011:51(Suppl 1):S8-20.

26. Levy H, Gutierrez I. Documentation and benchmarking of health insurance measures in the Health and Retirement Rtudy. 2009. Available at: https://hrs. isr.umich.edu/publications/biblio/5781.

27. Meng $H, H e X Z$, Dixon D. Self-reported versus measured height and weight in the health and retirement study. J Am Geriatr Soc. 2010;58:412-3.

28. U.S. Department of Commerce. Bureau of Economic Analysis Website. 2014. Available at:https://bea.gov/iTable/index_nipa.cfm. Updated: September 29, 2014. Accessed: 17 Oct, 2014

29. RAND Enhanced HRS Fat Files | RAND. Available at: https://www.rand.org/ labor/aging/dataprod/enhanced-fat.html. (Accessed: 28 Mar 2017).

30. Williams RL. A note on robust variance estimation for cluster-correlated data. Biometrics. 2000;56:645-6.

31. Cao B. Estimating the effects of obesity and weight change on mortality using a dynamic causal model. PLoS One. 2015;10:e0129946.

32. Stapleton RD, Dixon AE, Parsons PE, Ware LB, Suratt BT. The association between body mass index and plasma cytokine levels in patients with acute lung injury. Chest. 2010). doi:chest.10-0014 [pii]; https://doi.org/10. 1378/chest.10-0014

33. Weber MA, Neutel JM, Smith DH. Contrasting clinical properties and exercise responses in obese and lean hypertensive patients. J Am Coll Cardiol. 2001;37:169-74.

34. Langouche $\mathrm{L}$, et al. Critical illness induces alternative activation of $M 2$ macrophages in adipose tissue. Crit Care Lond Engl. 2011;15:R245.

35. Mancuso $P$, et al. Leptin-deficient mice exhibit impaired host defense in gram-negative pneumonia. J Immunol Baltim Md. 2002;168:4018-24.

36. Herridge MS, et al. One-year outcomes in survivors of the acute respiratory distress syndrome. N Engl J Med. 2003;348:683-93. 
37. Parameswaran $\mathrm{K}$, Todd DC, Soth M. Altered respiratory physiology in obesity. Can Respir J J Can Thorac Soc. 2006;13:203-10.

38. Das SR, et al. Impact of body weight and extreme obesity on the presentation, treatment, and in-hospital outcomes of 50,149 patients with ST-segment elevation myocardial infarction: results from the NCDR (National Cardiovascular Data Registry). J Am Coll Cardiol. 2011;58:2642-50.

39. Steinberg BA, et al. Medical therapies and invasive treatments for coronary artery disease by body mass: the 'obesity paradox' in the get with the guidelines database. Am J Cardiol. 2007;100:1331-5.

40. Diercks DB, et al. The obesity paradox in non-ST-segment elevation acute coronary syndromes: results from the can rapid risk stratification of unstable angina patients suppress ADverse outcomes with early implementation of the American College of Cardiology/American Heart Association guidelines quality improvement initiative. Am Heart J. 2006;152:140-8.

Submit your next manuscript to BioMed Central and we will help you at every step:

- We accept pre-submission inquiries

- Our selector tool helps you to find the most relevant journal

- We provide round the clock customer support

- Convenient online submission

- Thorough peer review

- Inclusion in PubMed and all major indexing services

- Maximum visibility for your research

Submit your manuscript at www.biomedcentral.com/submit
Biomed Central 